\title{
Geriatric Otorhinolaryngology, Head and Neck Emergency in a Nigerian Teaching Hospital, Ado Ekiti
}

\author{
Waheed Atilade Adegbiji', Shuaib Kayode Aremu' ${ }^{2}$, Abdul-Akeem A. Aluko ${ }^{3}$ \\ ${ }^{1}$ ENT Department, Ekiti State University Teaching Hospital, Ado Ekiti, Nigeria \\ ${ }^{2}$ ENT Department, Federal Teaching Hospital Ido-Ekiti, Afe-Babalola University, Ado-Ekiti, Nigeria \\ ${ }^{3}$ ENT Department, Aminu Kano Teaching Hospital, Bayero University, Kano, Nigeria \\ Email: *shuaib.aremu@gmail.com
}

How to cite this paper: Adegbiji, W.A., Aremu, S.K. and Aluko, A.-A.A. (2019) Geriatric Otorhinolaryngology, Head and Neck Emergency in a Nigerian Teaching Hospital, Ado Ekiti. International Journal of Otolaryngology and Head \& Neck Surgery, 8, 81-90.

https://doi.org/10.4236/ijohns.2019.83009

Received: March 13, 2019

Accepted: April 5, 2019

Published: April 8, 2019

Copyright $\odot 2019$ by author(s) and Scientific Research Publishing Inc. This work is licensed under the Creative Commons Attribution International License (CC BY 4.0).

http://creativecommons.org/licenses/by/4.0/

\begin{abstract}
Background: Issues of geriatric otolaryngologic emergency have not been widely applied despite an increase in the geriatric population. This study aimed at determining the prevalence, sociodemographic features, etiology, clinical features, complications and sources of referral of geriatric otorhinolaryngological, head and neck emergency in our center. Materials and Methods: This was a prospective hospital-based study of geriatric otorhinolaryngology emergency in the Ear, Nose and Throat Department of Ekiti State University Teaching Hospital. The study was carried out between October 2016 and September 2018. Data were obtained by using a pretested interviewers questionnaire. All data were collated and analyzed using SPSS version 18.0. The data were expressed by frequency table, percentage, bar charts, and pie charts. Results: Geriatric otorhinolaryngology, head and neck emergency accounted for $5.3 \%$. Major prevalence age group was $43.9 \%$ in the age group (60 - 64). There were $38.6 \%$ of males with a male to female ratio of 1:1.5. The main etiology of geriatric otorhinolaryngology emergency was $29.5 \%$ trauma/road traffic accident/foreign body impaction and $25.8 \%$ tumor. Main anatomical distribution of geriatric otorhinolaryngology emergency was $38.6 \%$ throat diseases and $31.1 \%$ ear diseases. The most frequent clinical features were the pain in $27.3 \%$, hearing loss in $21.2 \%$, tinnitus in $15.9 \%$, bleeding in $14.4 \%$, difficulty breathing in $12.9 \%$ and discharge in $11.4 \%$. Common diagnosis in this study was $15.9 \%$ sinonasal tumor, $14.4 \%$ upper aerodigestive foreign body impaction, $10.6 \%$ earwax impaction and $19.8 \%$ otitis externa. Acute presentation ( $<13$ weeks) occurred in 1 week in $74.2 \%$ and $2-13$ weeks in $19.7 \%$. Commonest time of presentation was daytime in $65.9 \%$. Major sources of referral were $43.2 \%$ general practitioner and $31.1 \%$ casualty offic-
\end{abstract}


ers. Presentation of geriatric otorhinolaryngology emergency was mainly ear, nose and throat clinic in 59.8\% with accident and emergency in $28.8 \%$. Commonest associated comorbid illnesses among the geriatric patients were 18.2\% hypertension, $14.4 \%$ arthritis, and $9.8 \%$ diabetes mellitus. Conclusion: Geriatric otorhinolaryngological emergency is a common pathology associated with comorbid illnesses. Detailed clinical assessment is mandatory for effective management outcome.

\section{Keywords}

Emergency, Geriatric, Head, Neck, Otorhinolaryngology

\section{Introduction}

Geriatric otorhinolaryngology is a relatively new emerging ear, nose and throat subspecialty which developed in response to the health challenges from a rise in life expectancy worldwide [1] [2]. The rise in life expectancy is more rapid in developed countries than in developing countries and this is associated with increased health challenges to the health workers and government [3] [4] [5]. This is due to the advancement of medical knowledge and its application through health services [6] [7] [8].

Geriatric Otorhinolaryngologic emergency health care is an integral part of any discipline of ear, nose and throat health practice and it is considered as an indicator of quality health care system. There is a need for every specialist hospital to have specialized emergency services to manage all forms of emergencies in ear, nose, throat, head, and neck round the clock.

Geriatric otorhinolaryngologic illnesses and injuries are common clinical disorders which are encountered in general otolaryngologic emergencies practices. In the elderly due to the aging phenomenon, cognitive impairment and associated comorbid diseases there may be alteration of these diseases presentation. All these may make it difficult for geriatric patients to provide an accurate history with difficulty in arriving at accurate diagnosis and management. The challenges of the elderly ear, nose and throat patients for the otorhinolaryngologist, head and neck surgeon in the emergency room have been a perennial discussion [9] [10] [11] [12].

There is a paucity of the study on geriatric otorhinolaryngologic, head and neck emergencies in developing countries and Nigeria in particular. This study aimed at determining the prevalence, sociodemographic features, etiology, clinical features, complications and sources of referral of geriatric otorhinolaryngological, head and neck emergency in our center.

\section{Materials and Methods}

This was a prospective hospital-based study of geriatric patients who presented with history and clinical features of otorhinolaryngology emergency in the Ear, 
Nose and Throat Department of Ekiti State University Teaching Hospital, Ado Ekiti, Nigeria. The study was carried out between October 2016 and September 2018.

Consent was obtained from the patients. All the consented geriatric patients with ear, nose, and throat emergency were enrolled in the study. A pretested semi-structured self-administered questionnaire was designed and used to collect data.

Data were obtained by using a pretested interviewers questionnaire. Data obtained from each patient during the study included Sociodemographic data, presenting symptoms, duration of symptoms and pre-hospital and hospital management. $\mathrm{P} \leq 0.05$ was taken as significant. These were followed by detailed ear, nose and throat examination. All findings on history and examinations were documented.

Treatment interventions for emergency cares were noted. Associated complications from the emergency or its pre-hospital and hospital treatments were also documented.

All data were collated and analyzed using SPSS version 18.0. The data were expressed by the frequency table, percentage, bar charts, and pie charts.

Ethical clearance for this study was sought for and obtained from the ethical committee of the institution.

\section{Results}

Geriatric otorhinolaryngology, head and neck emergency accounted for 132 (5.3\%) of the 2473 patients seen in our ear, nose and throat department during the study period.

The major prevalence age group of the geriatric otorhinolaryngology, head, and neck emergency was 58 (43.9\%) in the age group (60 - 64). Followed by 22 (16.7\%), 19 (14.4\%) and 16 (12.1\%) in the age group (65 - 69), (70 - 74) and (7579) years respectively. Age group distribution of the patients is shown in Table 1.

There were 51 (38.6\%) males and $81(61.4 \%)$ females with a male to female ratio of 1:1.5. Urban dwellers in 74 (56.1\%) were predominant over rural dwellers in 58 (43.9\%). The common form of education among the patients was posted secondary, no formal and secondary education in 38 (28.8\%), 34 (25.8\%) and 32 (24.2\%) respectively. Majority of the patient's occupation was $31(23.5 \%)$ civil servants, 27 (20.5\%) industrial workers, and 25 (18.9\%) farming. Table 2 illustrated the sociodemographic features of the patients.

The main aetiology of geriatric otorhinolaryngology, head and neck emergency was 39 (29.5\%) trauma/road traffic accident/foreign body impaction, 34 (25.8\%) tumour, 23 (17.4\%) infection/inflammationand 21 (15.9\%) ageing (degenerative). Table 3 demonstrated the aetiology among the patients.

Anatomical distribution of geriatric otorhinolaryngology, head, and neck emergency were 51 (38.6\%) throat diseases, 41 (31.1\%) ear diseases and $28(21.2 \%)$ 
nose diseases. Figure 1 showed the anatomical distribution of the emergency among patients.

The most frequent clinical features of the geriatric otorhinolaryngology, head and neck emergency in this study were pain in 36 (27.3\%), hearing loss in 28 (21.2\%), tinnitus in 21 (15.9\%), bleeding in 19 (14.4\%), difficulty breathing in 17 (12.9\%) and discharge in 15 (11.4\%). Table 4 demonstrated clinical features of emergency among the patients. Common diagnosis of geriatric otorhinolaryngology, head and neck emergency among the patients were 21 (15.9\%) sinonasal tumour, 19 (14.4\%) upper aerodigestive foreign body impaction, 14 (10.6\%) earwax impaction, 13 (19.8\%) otitis externa, 12 (9.1\%) pharyngotonsillitis and 11 (8.3\%) pharyngeal tumour. Table 5 showed a diagnosis of emergency among geriatric patients.

There was an acute presentation ( $<13$ weeks) otorhinolaryngology emergency of both 1 week in $98(74.2 \%)$ and 2 - 13 weeks. In 26 (19.7\%) and were commoner than chronic otorhinolaryngology emergency ( $\geq 13$ weeks) in 29 (7.5\%). Duration of emergency prior to presentation is illustrated in Figure 2.

In this study, commonest time of presentation of geriatric otorhinolaryngology, head, and neck emergency was daytime in 87 (65.9\%). The other presentation was at night and late night in $24(18.2 \%)$ and 21 (15.9\%) respectively. Figure 3 demonstrated time of presentation among the patients. Major sources of referral were from 57 (43.2\%) general practitioner, 41 (31.1\%) casualty officers, and $22(16.7 \%)$ self-reporting. Table 6 sources of referral among the patients.

Presentation of geriatric otorhinolaryngology, head, and neck emergency were ear, nose and throat outpatient clinic in 79 (59.8\%), accident and emergency in $38(28.8 \%)$ and hospital ward in 15 (11.4\%). Figure 4 illustrated pattern of presentation among the patients.

In this study, commonest associated comorbid illnesses among geriatric patients were hypertension in 24 (18.2\%). Other associated comorbid illnesses were $19(14.4 \%)$ arthritis, $13(9.8 \%)$ diabetes mellitus and 11 (8.3\%) cardiopulmonary diseases. Table 7 illustrated comorbid illnesses among geriatric otorhinolaryngology, head and neck emergency.

Table 1. Age group distribution of the patients.

\begin{tabular}{ccc}
\hline Age group (year) & Number & Percentage (\%) \\
\hline $60-64$ & 58 & 43.9 \\
$65-69$ & 22 & 16.7 \\
$70-74$ & 19 & 14.4 \\
$75-79$ & 16 & 12.1 \\
$80-89$ & 8 & 6.1 \\
$90-94$ & 5 & 3.8 \\
$95-99$ & 3 & 2.3 \\
$\geq 100$ & 1 & 0.8 \\
Total & 132 & 100 \\
\hline
\end{tabular}


Table 2. Sociodemographic features among the patients.

\begin{tabular}{ccc}
\hline Sociodemographic features & Number & Percentage (\%) \\
\hline Sex & 51 & 38.6 \\
Male & 81 & 61.4 \\
Female & & \\
Residential & 74 & 56.1 \\
Urban & 58 & 43.9 \\
Rural & & \\
Education level & 34 & 25.8 \\
No formal education & 28 & 21.2 \\
Primary & 32 & 24.2 \\
Secondary & 38 & 28.8 \\
Post-secondary & & \\
Patients/parents occupation & 31 & 23.5 \\
Civil servants & 19 & 14.4 \\
Business & 18 & 13.6 \\
Driver & 27 & 20.5 \\
Industrial worker & 25 & 18.9 \\
Farming & 12 & 9.1 \\
Artisans & &
\end{tabular}

Table 3. Aetiology among patients.

\begin{tabular}{ccc}
\hline Aetiology & Number & Percentage (\%) \\
\hline Trauma/RTA/Foreign body & 39 & 29.5 \\
Infection/inflammation & 23 & 17.4 \\
Tumour & 34 & 25.8 \\
Functional disorder & 9 & 6.8 \\
Idiopathic & 6 & 4.5 \\
Ageing (degenerative) & 21 & 15.9 \\
\hline
\end{tabular}

Table 4. Clinical features of the emergency among the patients.

\begin{tabular}{ccc}
\hline Clinical features & Number & Percentage (\%) \\
\hline Foreign body impaction & 12 & 9.1 \\
Difficulty breathing & 17 & 12.9 \\
Pain & 36 & 27.3 \\
Discharge & 15 & 11.4 \\
Tinnitus & 21 & 15.9 \\
Hearing loss & 28 & 21.2 \\
Lacerations & 12 & 9.1 \\
Bleeding & 19 & 14.4 \\
Nasal blockage & 13 & 9.8 \\
Hoarseness & 8 & 6.1 \\
Odynophagia/dysphagia & 9 & 6.8 \\
Vertigo & 11 & 8.3 \\
Mass/swelling & 12 & 9.1 \\
Halitosis & 7 & 5.3 \\
\hline
\end{tabular}


Table 5. Diagnosis of emergency among the geriatric patients.

\begin{tabular}{ccc}
\hline Diagnosis & Number & Percentage (\%) \\
\hline Otitis externa & 13 & 9.8 \\
Ear Foreign body impaction & 5 & 3.8 \\
Earwax impaction & 14 & 10.6 \\
Benign paroxysmal positional vertigo & 7 & 5.3 \\
Meniere's disease & 2 & 1.5 \\
Nasal Septal abscess & 2 & 1.5 \\
Sinonasal tumor & 21 & 15.9 \\
Midfacial fracture & 5 & 3.8 \\
Pharyngotonsillitis & 12 & 9.1 \\
Pharyngeal tumor & 11 & 8.3 \\
Laryngeal tumor & 9 & 6.8 \\
Neck space abscess & 19 & 14.4 \\
Cervical lymphadenopathy & 3 & 2.3 \\
Temporomandibular joint arthritis & 4 & 3.0 \\
\hline
\end{tabular}

Table 6. Sources of referral among the patients.

\begin{tabular}{ccc}
\hline Sources of referral & Number & Percentage (\%) \\
\hline Self-reporting & 22 & 16.7 \\
General practitioner & 57 & 43.2 \\
Casualty officer & 41 & 31.1 \\
Others & 12 & 9.1 \\
\hline
\end{tabular}

Table 7. Comorbid illnesses among geriatric otorhinolaryngology, head and neck emergency.

\begin{tabular}{ccc}
\hline Compilations & Number & Percentage (\%) \\
\hline Diabetes mellitus & 13 & 9.8 \\
Hypertension & 24 & 18.2 \\
Arthritis & 19 & 14.4 \\
Cardiopulmonary diseases & 11 & 8.3 \\
Neuropathy & 4 & 3.0 \\
Ocular diseases & 5 & 3.8 \\
\hline
\end{tabular}

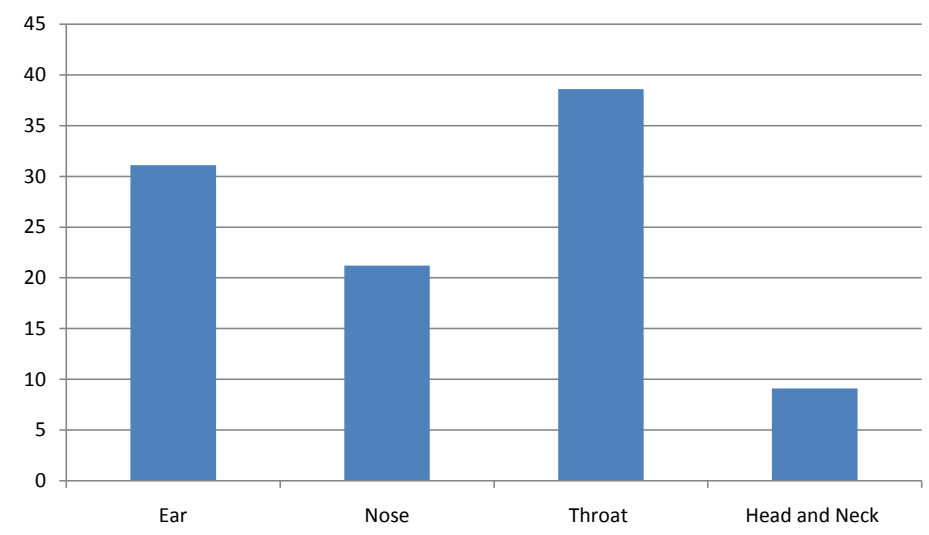

Figure 1. Anatomical distribution of the emergency among patients. 


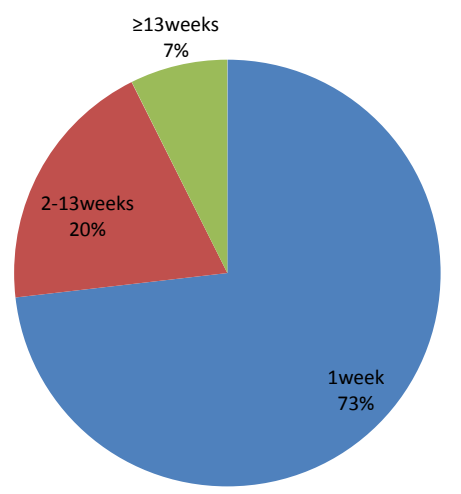

Figure 2. Duration of emergency prior to presentation.

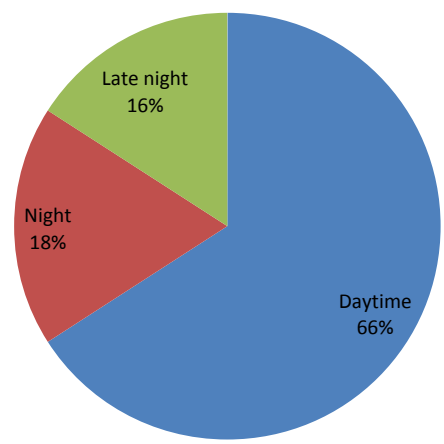

Figure 3. Time of presentation among the patients.

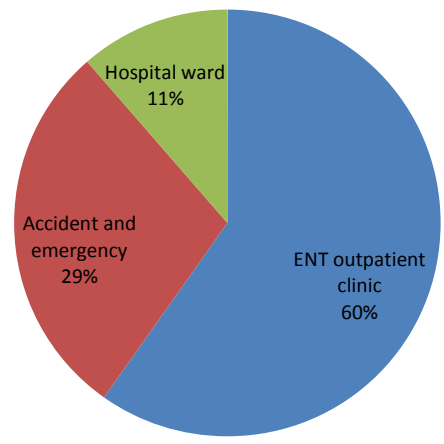

Figure 4. Pattern of presentation among the patients.

\section{Discussion}

Geriatric otorhinolaryngologic emergency conditions are common otorhinolaryngologic workload in our institution with high prevalence as noted in this study. This is similar to the report of other studies in Nigeria and beyond [13] [14]. This is because geriatrics population is on the rise worldwide which has led to its projected increase in the near future even in developing countries due to global human development report released by the United Nations Development Programme (UNDP) [15].

Sociodemographic features of geriatric emergency in this study revealed a high prevalence of age group 60 - 64 years, female preponderance and predomi- 
nant urban dwellers. These findings are contrary to findings in other studies [16] [17]. This could be due to the geographical difference in the study population. The finding is however similar to report from a study done southern part of $\mathrm{Ni}$ geria [18].

Common etiology of geriatric emergency in this study was trauma/road traffic accident/foreign body impaction, infection/inflammation and tumor these are due to degenerative changes in all the body organs functional. Similar findings were reported in other studies [19] [20]. These accounted for the commonest distribution of throat and ear pathology in our findings in a geriatric otorhinolaryngological emergency. Contrary findings were reported from other studies in the southern and western part of Nigerian [21] [22].

Most common diseases were a sinonasal tumor, upper aerodigestive foreign body impaction, earwax impaction, otitis externa, pharyngotonsillitis and pharyngeal tumor in this study. This leads to the common clinical presentation of pain, hearing loss, tinnitus, bleeding, difficulty breathing, discharge, and nasal blockage. This concurs with other research workers on elderly emergency otorhinolaryngology [23] [24].

Geriatric otorhinolaryngologic emergency conditions are similar to other forms of emergencies with the mostly early presentation, common presentation during the day time and were referred mainly by general practitioners or casualty officers [25].

The process of aging leads degenerative changes with resultant organs dysfunction among the geriatric patients. This leads to the associated comorbid illnesses in geriatric patients which must be ruled out by detailed clinical assessment. The major comorbid illnesses in this study were hypertension, arthritis, diabetes mellitus, and cardiopulmonary diseases. A similar finding was reported in other studies [26] [27] [28].

\section{Conclusion}

The geriatric otorhinolaryngological emergency is a common pathology. They are associated with comorbid illnesses and disabilities at presentation. Detailed clinical assessment is mandatory for effective management outcome. Provision of adequate personnel and equipment by policymakers are strongly advised.

\section{Limitation}

The study was a hospital-based study and such the data may not absolutely represent what is obtained in the entire community.

\section{Funding}

There was no financial support. It is a self-sponsored research study.

\section{Acknowledgements}

The authors are most grateful to Ekiti state university teaching hospital, the staff 
and all the patients who participated in this study.

\section{Conflicts of Interest}

All the authors declare that there were no competing interests.

\section{References}

[1] Goldstein, J.C. (2007) The American Society of Geriatric Otolaryngology. Ear, Nose \& Throat Journal, 86, 718-719.

[2] Dagan, E., Wolf, M. and Migirov, L. (2012) Why Do Geriatric Patients Attend Otolaryngology Emergency Rooms? The Israel Medical Association Journal, 14, 633-636.

[3] (2007) Selected Data for the International Senior Citizen's Day. Israel Central Bureau of Statistics, Jerusalem.

[4] Roberts, D.C., McKay, M.P. and Shaffer, A. (2008) Increasing Rates of Emergency Department Visits for Elderly Patients in the United States, 1993 to 2003. Annals of Emergency Medicine, 51, 769-774.

https://doi.org/10.1016/j.annemergmed.2007.09.011

[5] Aminzadeh, F. and Dalziel, W.B. (2002) Older Adults in the Emergency Department: A Systematic Review of Patterns of Use, Adverse Outcomes, and Effectiveness of Interventions. Annals of Emergency Medicine, 39, 238-247. https://doi.org/10.1067/mem.2002.121523

[6] Zafar, S.N., Ganatra, H.A., Tehseen, S. and Qidwai, W. (2006) Health and Needs Assessment of Geriatric Patients: Results of a Survey at a Teaching Hospital in Karachi. Journal of Pakistan Medical Association, 56, 470-474.

[7] Population Reference Bureau. The 2006 World Health Data Sheet, Washington DC.

[8] Itrat, A., Taqui, A.M., Qazi, F. and Qidwai, W. (2007) Family System: Perceptions of Elderly Patients and Their Attendants Presenting at a University Hospital in Karachi, Pakistan. Journal of Pakistan Medical Association, 57, 106-109.

[9] Adams, J.G. and Gerson, L.W. (2003) A New Model for Emergency Care of Geriatric Patients. Academic Emergency Medicine, 10, 271-273.

[10] Chalian, A.A. (2009) Accomplishment and Opportunity in Geriatric Otolaryngology. Ear, Nose \& Throat Journal, 88, 1156-1161.

[11] Sarkar, S., Roychoudhury, A. and Roychaudhuri, B.K. (2010) Foreign Bodies in ENT in a Teaching Hospital in Eastern India. Indian Journal of Otolaryngology and Head \& Neck Surgery, 62, 118-120.

[12] Bauer, C.A. and Konrad, H.R. (2006) Peripheral Vestibular Disorders. In: Bailey, B.J., Ed., Head and Neck Surgery-Otolaryngology, 4th Edition, Lippincott Williams and Wilkins, Philadelphia, 2295-2302.

[13] Sorenson, B. (1990) Injuries of the Ear, Nose, and Throat Encountered at a Casualty Department. A One-Year Caseload. Ugeskrift for Læger, 152, 739-743.

[14] Lasisi, O.A., Imam, Z.K. and Adeosun, A.A. (2006) Otorhinolaryngologic Emergencies in Nigeria, Sub-Saharan Africa: Implication for Training. East and Central African Journal of Surgery, 12, 48-52.

[15] Sehgal, R.K., Garg, R., Anand, S. and Dhot, P.S. (2015) The Analysis of the Rural Outreach Programme of a Tertiary Care Hospital in Ghaziabad and the Morbidity Profile of Out-Patients Attending the Programme. Journal of Medical and Dental Sciences, 4, 9561-9567. https://doi.org/10.14260/jemds/2015/1382 
[16] Rahman, M.W., Ahasan, A.I., Debnath, T.K., Jamil, A.N.M., Barua, R. and Amin, M.N. (2015) Study on Hearing Status of Elderly Patients Attending a Specialized ENT Hospital (SAHIC). Bangladesh Journal of Otorhinolaryngology, 21, 80-84. https://doi.org/10.3329/bjo.v21i2.27644

[17] Opoku-Buabeng, J. (2012) Ear, Nose and Throat Manifestations in Geriatrics. Journal of Science and Technology, 32, 18-23.

[18] Onotai, L.O. and Ureh, O. (2017) Otological Diseases amongst Elderly Patients in Port Harcourt, Nigeria-A 15 Years Review. Global Journal of Otolaryngology, 6, Article ID: 555682.

[19] Kishore, S., Juyal, R., Semwal, J. and Chandra, R. (2007) Morbidity Profile of Elderly Persons. JK Science, 9, 87-89.

[20] Srivastava, K., Gupta, S.C., Kaushal, S.C. and Chaturvedi, M. (2010) Morbidity Profile of Elderly: A Cross Sectional Study of Urban Agra. Indian Journal of Community Health, 21, 51-55.

[21] Okoye, B.C. and Onotai, L.O. (2007) Pattern of Geriatrics Otolaryngologcal Diseases in Port Harcourt. Nigerian Journal of Medicine, 16, 239-241.

[22] Ogunleye, A.O.A., Ibekwe, T.S. and Ijaduola, G.T.A. (2005) Otorhinolaryngology and Geriatrics in Ibadan. Niger. J. Otorhinolaryngol., 2, 7-12.

[23] Palchun, V.T., Kunel skaia, N.L. and Kislova, N.M. (1998) Emergency Diseases of the Ear (Comparative Data). Vestnik Oto-Rino-Laringologii, 6, 4-10.

[24] Huang, S.E., Hung, H.Y., Jou, W.B. and Lin, W.S. (1991) An Epidemiological Study of Otolaryngologic Emergency Diseases. Chinese Medical Journal, 48, 456-461.

[25] Ibekwe, U.M. (2017) Otorhinolaryngological Emergencies in a Tertiary Hospital in Port Harcourt. Nigerian Journal of Clinical Practice, 20, 606-609.

https://doi.org/10.4103/1119-3077.196988

[26] Khan, M.A., Mushtaq, M., Ahmad, M.Z., Amir, H., Bajwa, T.M. and Laeeque, S.M. (2012) Prevalence of Geriatric Diseases among Parents of Medical Doctors in Lahore. Journal of Ayub Medical College Abbottabad, 24, 133-135.

[27] Nepali, R., Sigdel, B. and Tuli, B.S. (2014) Study of ENT Diseases in Geriatric Population at Gandaki Medical College Teaching Hospital. Journal of Gandaki Medical College Nepal, 7, 15-18.

[28] Pyakurel, M., Bhatta, R. and Pokharel, R. (2014) Otorhinolaryngological Problem in Geriatric Population. Nepalese Journal of ENT, Head \& Neck Surgery, 5, 23-25. https://doi.org/10.3126/njenthns.v5i2.19423 